\title{
Preparation and structural investigation of Polyethylene glycol (PEG) / nano-ferrite composites
}

\begin{abstract}
S. A. Saafan*, N. M. Abo-aita, E. H. El-Ghazzawy
Physics Department, Faculty of Science, Tanta University, Tanta 31527, Egypt

Abstract

Polyethylene glycol(PEG)/nano-ferrite composites have been prepared by using $\mathrm{CoFe}_{2} \mathrm{O}_{4}, \mathrm{CuFe}{ }_{2} \mathrm{O}_{4}, \mathrm{Co}_{0.5} \mathrm{Cu}_{0.5} \mathrm{Fe}_{2} \mathrm{O}_{4}$ and $\mathrm{MgFe}_{2} \mathrm{O}_{4}$ ferrite nano-particles synthesized by citrate precursor method along with PEG with different percentages. Ferrite samples have been characterized by X-ray diffraction (XRD) to confirm the formation of pure spinel ferrite phase and, transmission electron microscopy (TEM) to ensure that the average particle size is within the nano-scale. Thermo-gravimetric analysis (TGA) and differential scanning calorimetry (DSC) thermographs of the ferrite samples have been used to ensure the complete formation of pure ferrites at temperatures above $800^{\circ} \mathrm{C}$. The ferrites and their composites with PEG, have been investigated by FTIR spectroscopy. The main bands of ferrites and PEG have been clearly displayed in agreement with literature. A systematic shift of the bands has been observed upon adding PEG. The magnetic properties have been explored by using the vibrating sample magnetometer (VSM). Where are the values of of saturation magnetization $\left(M_{s}\right)$, remnant magnetization $\left(M_{r}\right)$ and coercive field $\left(H_{c}\right)$ for pure ferrite and composite samples vary with the presence of different divalent cations which have different magnetic moment. Whereas a $H_{c}$ values remain constant as obtained in pure ferrites regardless the ratio of PEG. The obtained values of $H_{c}$ are comparable with those in literature, which can be used in electromagnetic wave attenuation.
\end{abstract}

Keywords: Ferrites; PEG- nano-composites; magnetic properties; structural properties; thermal properties.

\section{Paper information:}

Receive Date: 28 September 2021; Revise Date: 7 November 2021; Accept Date: 11 November 2021;

Publish Date: 12 November 2021

${ }^{*}$ Corresponding Author: samiasaafan@science.tanta.edu.eg 


\section{Introduction}

Ferrites are well known ferrimagnetic complex metal oxides characterized by high magnetic susceptibility and high electrical resistivity at the same time, but their properties may vary largely depending on the chemical formula, the method of synthesis, the amount of doping and/or the type of the substituted cations, and also very strongly on the particle size [1-5] Pure ferrites are heavy brittle ceramics and may not be suitable for some applications requiring light weight, malleability and flexibility. Therefore, more suitable candidates for such applications may be polymer composites containing ferrite particles instead of pure ferrites in order to decrease the weight of the materials and to increase their malleability and/or flexibility. Important examples of such applications of nano ferrite-containing composites are EMI suppressors [6], chemical and electrical energy storage devices, sensors , phase shifters, switches, catalysts, magnetic hyperthermia and magnetic field assisted drug delivery [7-9].

Returning to ferrites, it is known that $\mathrm{CoFe}_{2} \mathrm{O}_{4}, \mathrm{CuFe}_{2} \mathrm{O}_{4}$, and $\mathrm{MgFe}_{2} \mathrm{O}_{4}$ are very important spinel ferrites, extensively studied, for having properties which can be tuned by varying preparation conditions [10], and for their relatively low cost of preparation, excellent combination of magnetic and dielectric properties to attain requirements for high frequency applications [11,12].

On the other hand, the polymer PEG consists of ethylene oxide and water having a chemical formula: $\mathrm{H}\left(\mathrm{OCH}_{2} \mathrm{CH}_{2}\right)_{\mathrm{n}} \mathrm{OH}$; where $\mathrm{n}$ is the average number of repeating oxyethylene groups ranging from 4 up to 180 . PEG is nontoxic, odorless, nonirritating for human skin and nonvolatile. It is used in a variety of pharmaceuticals and in medications as a solvent $[13,14]$. PEG is biocompatible and biodegradable too. PEG coating may enhance the compatibility between an aqueous medium and ferrite nanoparticles. It had recorded success in preventing particle surface from oxidation. It has reduced toxicity, and facilitated storage and/or transport [15]. Also, the properties of PEG/ferrite nano-composites can be adjusted by changing the divalent cation incorporated into the ferrite structure [16].

Therefore, according to the expected promising applications of different PEG/nano particle-ferrite composites, the present work reports the synthesis of $\mathrm{CoFe}_{2} \mathrm{O}_{4}, \mathrm{CuFe}_{2} \mathrm{O}_{4}$, $\mathrm{Co}_{0.5} \mathrm{Cu}_{0.5} \mathrm{Fe}_{2} \mathrm{O}_{4}$ and $\mathrm{MgFe}_{2} \mathrm{O}_{4}$ in nano-particle size by using the citrate precursor method and the incorporation of these nanoparticle ferrites into polyethylene glycol (PEG) solution to prepare composites with different weight percentage of ferrites to PEG. Also, the investigation of some structural and thermal properties of those materials via XRD, TEM, TGA, DSC and FTIR, is reported. The magnetic properties and the cation distribution also are explored by VSM measurements.

In this manuscript, the variety of the divalent cations in the synthesized ferrite samples provided the opportunity to find different properties for multiple applications in the industrial and medical fields.

\section{Experimental procedures}

\subsection{Preparation of ferrite samples}

Nano ferrite samples with the forms $\mathrm{MgFe}_{2} \mathrm{O}_{4}, \mathrm{CoFe}_{2} \mathrm{O}_{4}, \mathrm{CuFe}_{2} \mathrm{O}_{4}$ and $\mathrm{Co}_{0.5} \mathrm{Cu}_{0.5} \mathrm{Fe}_{2} \mathrm{O}_{4}$ have been synthesized by using the citrate precursor method. This method is usually used to synthesize some magnetic oxide nano-particle due to its simplicity and time saving. The desired ferrite samples have been prepared by using the proper amounts of $\mathrm{Cu}\left(\mathrm{NO}_{3}\right)_{2} \cdot 3 \mathrm{H}_{2} \mathrm{O}$ (purity 98\% Oxford Lab.), $\mathrm{Co}\left(\mathrm{NO}_{3}\right)_{2} \cdot 6 \mathrm{H}_{2} \mathrm{O}$ (purity $97.9 \%$ fisher scientific) and 
$\mathrm{Mg}\left(\mathrm{NO}_{3}\right)_{3} .9 \mathrm{H}_{2} \mathrm{O}$ (purity $99 \%$ Oxford Lab.) and $\mathrm{Fe}\left(\mathrm{NO}_{3}\right)_{3} .9 \mathrm{H}_{2} \mathrm{O}$ (purity $97 \%$ fisher scientific) via the citrate precursor method.

The weights of the reactants are tabulated in Table 1. The procedure is as follows: Aquatic clear colored solutions have been made by dissolving the metal nitrates in a suitable amount of distilled water. Then, they have been kept in separated beakers at room temperature for 30 minutes. Then the solutions have been mixed and stirred continuously, at room temperature for 1 hour to ensure homogeneity. The citric acid has been added drop-wise to this solution, such that the molar ratio between the metal nitrates and the citric acid is maintained at 1:1. Then, ammonium hydroxide solution $33 \%$ has been added drop-wise to the solution until $\mathrm{pH}$ becomes higher than 8 . The final solution has been stirred for 30 minutes at room temperature and then heated to obtain highly viscous gel. With further heating period, the highly viscous gel starts ignition and burns out to form a tree like ferrite ash nanoparticles. The ferrite ash has been ground in an agate mortar.

Table 1: The weights of the reactants for preparing the ferrite samples.

\begin{tabular}{|c|c|c|c|c|}
\hline \multicolumn{5}{|c|}{ Ferrite samples } \\
\hline Reactants & $\mathrm{CoFe}_{2} \mathrm{O}_{4}$ & $\mathrm{Co}_{0.5} \mathrm{Cu}_{0.5} \mathrm{Fe}_{2} \mathrm{O}_{4}$ & $\mathrm{CuFe}_{2} \mathrm{O}_{4}$ & $\mathrm{MgFe}_{2} \mathrm{O}_{4}$ \\
\hline $\mathbf{C}_{6} \mathbf{H}_{8} \mathbf{O}_{7}$ & $49.115 \mathrm{~g}$ & $51.86 \mathrm{~g}$ & $48.168 \mathrm{~g}$ & $57.62 \mathrm{~g}$ \\
\hline $\mathrm{Fe}\left(\mathrm{NO}_{3}\right)_{3} \cdot 9 \mathrm{H}_{2} \mathrm{O}$ & $68.87 \mathrm{~g}$ & $72.72 \mathrm{~g}$ & $67.549 \mathrm{~g}$ & $80.8 \mathrm{~g}$ \\
\hline $\mathrm{Co}\left(\mathrm{NO}_{3}\right)_{2} \cdot 6 \mathrm{H}_{2} \mathrm{O}$ & $24.8 \mathrm{~g}$ & $13.096 \mathrm{~g}$ & - - & --------- \\
\hline $\mathrm{Cu}\left(\mathrm{NO}_{3}\right)_{2} \cdot 3 \mathrm{H}_{2} \mathrm{O}$ & ---------- & $10.87 \mathrm{~g}$ & $20.197 \mathrm{~g}$ & --------- \\
\hline $\mathrm{Mg}(\mathrm{NO3}) 2.6 \mathrm{H}_{2} \mathrm{O}$ & --------- & & ---------- & $25.643 \mathrm{~g}$ \\
\hline
\end{tabular}

XRD analysis (GNR APD 2000 Pro X-ray diffractometer (XRD) step scan type and $\mathrm{CuK}_{\alpha}$ radiation), TEM (JEOL JEM-100SX), DSC, TGA (TPS 500 Thermal constant Analyzer): and FTIR (Tensor 27) spectroscopy have been used for the identification of the four ferrite samples. The VSM has been used to estimate and detect the magnetic properties.

\subsubsection{A Brief description of the used techniques}

TEM (JEOL-100SX): In this technique, the tested specimen of ultrathin thickness (less than $100 \mathrm{~nm}$ thick) is suspended on a graphite grid and allowing an accelerated beam of electrons to transmit through it. An image is formed from the interaction of the electrons with the sample as the beam is transmitted through the specimen. The image is then magnified and focused by electromagnetic lenses onto an imaging device, such as a fluorescent screen then recorded by attached camera.

X-Ray (GNR, APD2000 PRO step scan): X-ray diffraction (XRD) is a technique used to determine the crystallographic structure of a material. XRD works by irradiating a material with incident monochromatic X-rays and then measuring the intensities and diffraction angles of the X-rays that leave the material. The peaks are obtained if the Brag`s law $(n \lambda=2 d \sin \theta)$ is verified at certain angles.

TGA (The Hot Disk TPS500 Thermal constant Analyzer): This system consists of a precision balance with a sample pan located inside a furnace with a programmable control temperature. The temperature is generally increased at constant rate (or for some applications the temperature is controlled for a constant mass loss) to perform a thermal reaction. The mass is continuously measured while the temperature of a sample is changed over time.

IR (Tensor 27): Infrared technique detects the interaction of infrared radiation with matter by absorption, emission, or reflection. It is used to study and identify chemical substances or functional groups in solid, liquid, or gaseous forms. The common technique is a Fourier transform infrared (FTIR) in which Infrared radiation is guided through an interferometer and then through the sample (or vice versa). A moving mirror inside the 
apparatus alters the distribution of IR radiation that passes through the interferometer. The signal directly recorded, called an "interferogram", represents light output as a function of mirror position. A data-processing technique called Fourier transform turns this raw data into the desired result (the sample's spectrum): Light output as a function of infrared wavelength (or equivalently, wavenumber). As described above, the sample's spectrum is always compared to a reference.

VSM (constructed and calibrated in our lab): in this technique the sample is attached to a vibrating rod placed in DC magnetic field. A pickup coil stacked on the electromagnet poles will generate induced voltage proportional to the magnetization produced in the sample. The data from pickup coil are plotted as $\mathrm{Y}$-axis while the data from the gauss meter are plotted as $\mathrm{X}$-axis. The obtained hysteresis loop used to extract the magnetic parameter of the sample.

\subsection{Preparation of nano-composite samples}

Polyethylene glycol (PEG) is dissolved in acetone and then ferrite nanoparticles are added to it with concentrations of 20,50 and $80 \mathrm{wt} . \%$ to prepare the polymer/ ferrite composites. After acetone evaporating, the remnant has been grinded in the agate mortar to obtain a very fine nano-composite powder.

All composite samples and the pure PEG sample have been characterized by FTIR spectroscopy and their magnetic properties have been explored by the VSM too.

\section{Results and discussion}

\subsection{XRD analysis and TEM images}

Figure (1) shows the XRD of all prepared samples $\left(\mathrm{CuFe}_{2} \mathrm{O}_{4}, \mathrm{CoFe}_{2} \mathrm{O}_{4}, \mathrm{MgFe}_{2} \mathrm{O}_{4}\right.$ and $\mathrm{Co}_{0.5} \mathrm{Cu}_{0.5} \mathrm{Fe}_{2} \mathrm{O}_{4}$ ). X-ray diffraction patterns confirm the formation of $\mathrm{CoFe}_{2} \mathrm{O}_{4}$ (JCPDS card. No 791744), $\mathrm{Mg} \mathrm{Fe} \mathrm{O}_{4}$ (JCPDS card No. 17- 464) and $\mathrm{CuFe}_{2} \mathrm{O}_{4}$ (JCPDS card No. 34-0425) which have a single-phase cubic spinel crystal structure. The recorded peaks represent the (111), (220), (311), (400), (422), (511) and (440) planes characterizing the structure of ferrites according to published literature $[17,18]$. Here, we can state as a first conclusion that the used citrate precursor technique has been a successful method for preparing the nanoferrite samples.

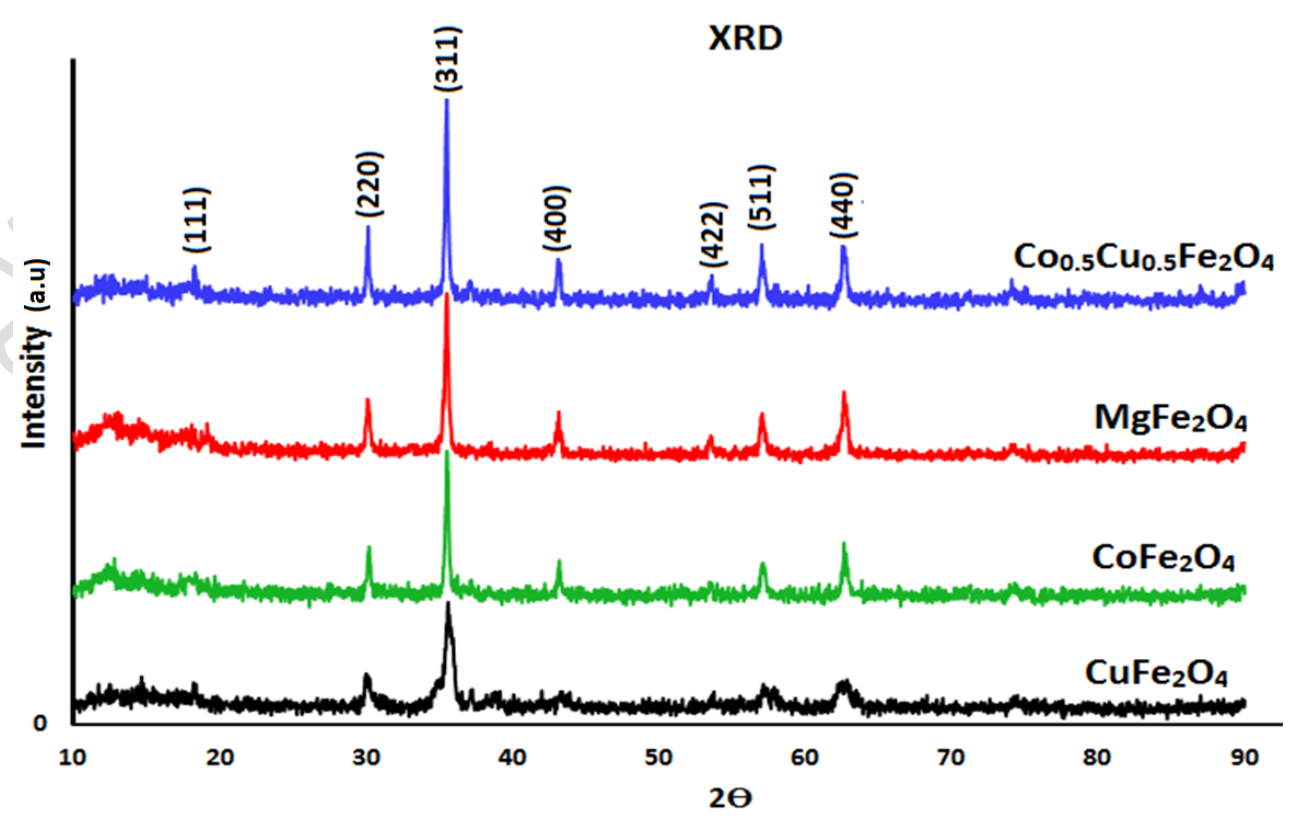

Fig. (1) XRD patterns of the prepared ferrite samples. 
Table (2) lists the average particle size calculated from the XRD data $(R)$ and from the images of TEM $\left(R_{T E M}\right)$, porosity $(P), \mathrm{X}$-ray density $\left(D_{x}\right)$, and lattice constant $(a)$ of the ferrite samples as calculated from the XRD data.

As shown in the table, the average particle size calculated from XRD $(R)$ has ranged from $35 \mathrm{~nm}$ to $53 \mathrm{~nm}$ whereas the average particle size calculated from the images of TEM (Figs 2, 3,4 and 5) has ranged from 44.46 to $56.92 \mathrm{~nm}$, these slight differences in the average particle sizes calculated from XRD and TEM can be easily explained by the well-known fact that the XRD detects the crystalline part of the particle only (i.e. the grain) as a result of Bragg's law, without detecting the disordered part of the particle (i.e. the grain boundary), whereas the TEM records the size of the whole particle (i.e. grain and grain boundary) [19]

Also, the X-ray density $D_{x}$ is seen to be directly proportional to the molecular weight in the same table, in spite of the existence of $(a)^{3}$ in the denominator of the mathematical formula of $D_{x}$ according to:

$$
D_{x}=\frac{8 M}{N_{A} a^{3}}
$$

which means that the effect of the molecular weight (in the numerator) on the theoretical density value is greater than the effect of the lattice parameter. The observed X- ray density $\left(D_{x}\right)$ have quite reasonable values in agreement with literature [12,20]. Moreover, the lattice parameter $a$ in all samples is in fair agreement with literature too [20]. The porosity is inversely proportional to the density, which is simply logical. Moreover, it is noticed that the porosity is inversely proportional to the particle size because smaller particles tend to pack more closely together than larger particles. In addition, it is observed that the trend of the lattice constant $(a)$ of $\mathrm{MgFe}_{2} \mathrm{O}_{4}, \mathrm{CuFe}_{2} \mathrm{O}_{4}$ and $\mathrm{CoFe}_{2} \mathrm{O}_{4}$ are in agreement with the published ionic radii of $\mathrm{Mg}^{2+}(0.78 \AA), \mathrm{Cu}^{2+}(0.70 \AA)$ and $\mathrm{Co}^{2+}(0.82 \AA)[21]$.

Table (2): The lattice constant $a(\AA)$, average particle size from XRD $R(\mathrm{~nm})$ and from TEM images $R_{T E M}(\mathrm{~nm})$, Porosity , measured density $D\left(\mathrm{~g} / \mathrm{cm}^{3}\right)$ and X-ray density $D_{x}\left(\mathrm{~g} / \mathrm{cm}^{3}\right)$.

\begin{tabular}{|c|c|c|c|c|c|c|c|}
\hline Sample & $\begin{array}{l}\text { Molecular } \\
\text { weight (g) }\end{array}$ & $a(\AA)$ & $\begin{array}{l}R(n m) \\
\text { XRD }\end{array}$ & $D\left(\mathrm{~g} / \mathrm{cm}^{3}\right)$ & $D_{x}\left(\mathrm{~g} / \mathrm{cm}^{3}\right)$ & $P=1-D / D_{x}$ & $\begin{array}{l}R_{T E M}(\mathrm{~nm}) \\
\text { From TEM }\end{array}$ \\
\hline $\mathrm{CuFe}_{2} \mathrm{O}_{4}$ & 239.232 & 8.359 & 38.51 & 2.80 & 5.44 & 0.49 & 44.46 \\
\hline $\mathrm{Co}_{0.5} \mathrm{Cu}_{0.5} \mathrm{Fe}_{2} \mathrm{O}_{4}$ & 222.353 & 8.365 & 53.33 & 2.35 & 5.05 & 0.53 & 55.33 \\
\hline $\mathrm{CoFe}_{2} \mathrm{O}_{4}$ & 234.620 & 8.381 & 37.47 & 1.08 & 5.29 & 0.80 & 56.92 \\
\hline $\mathrm{MgFe}_{2} \mathrm{O}_{4}$ & 199.991 & 8.380 & 35.55 & 2.14 & 4.51 & 0.53 & 47.93 \\
\hline
\end{tabular}

Figs. (2), (3), (4) and (5) as mentioned above display the TEM images of the pure ferrite samples. It is observed that the particles seem to be irregular agglomerations. The particle size distribution histogram is performed by analyzing the TEM images as shown in Figs ( $3 b$, $5 b)$. It is obvious that the particles have a wide range of particle size distribution. This may be due to the ignition stage in citrate precursor method which contribute to forming inhomogeneous particles. 

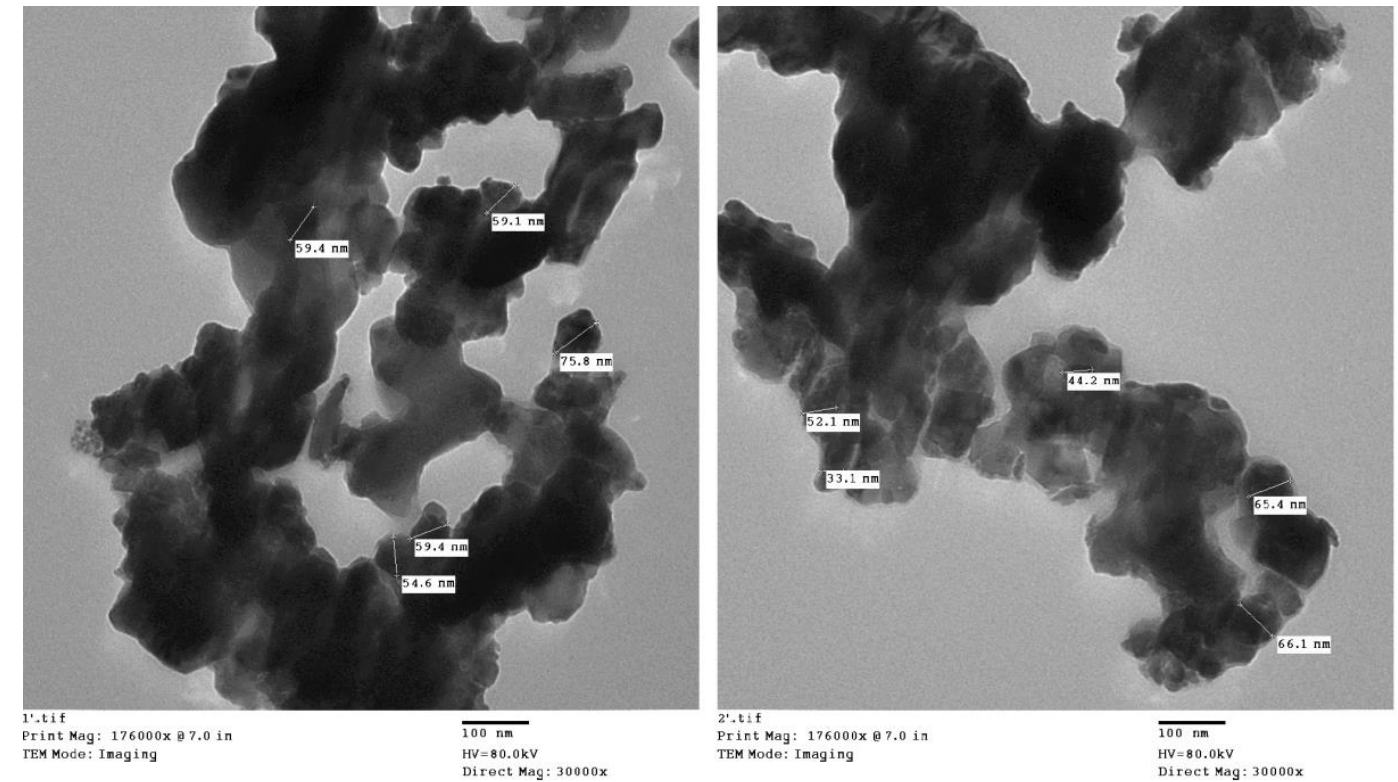

Fig. (2) TEM micrograph of $\mathrm{CoFe}_{2} \mathrm{O}_{4}$ nanoparticles.
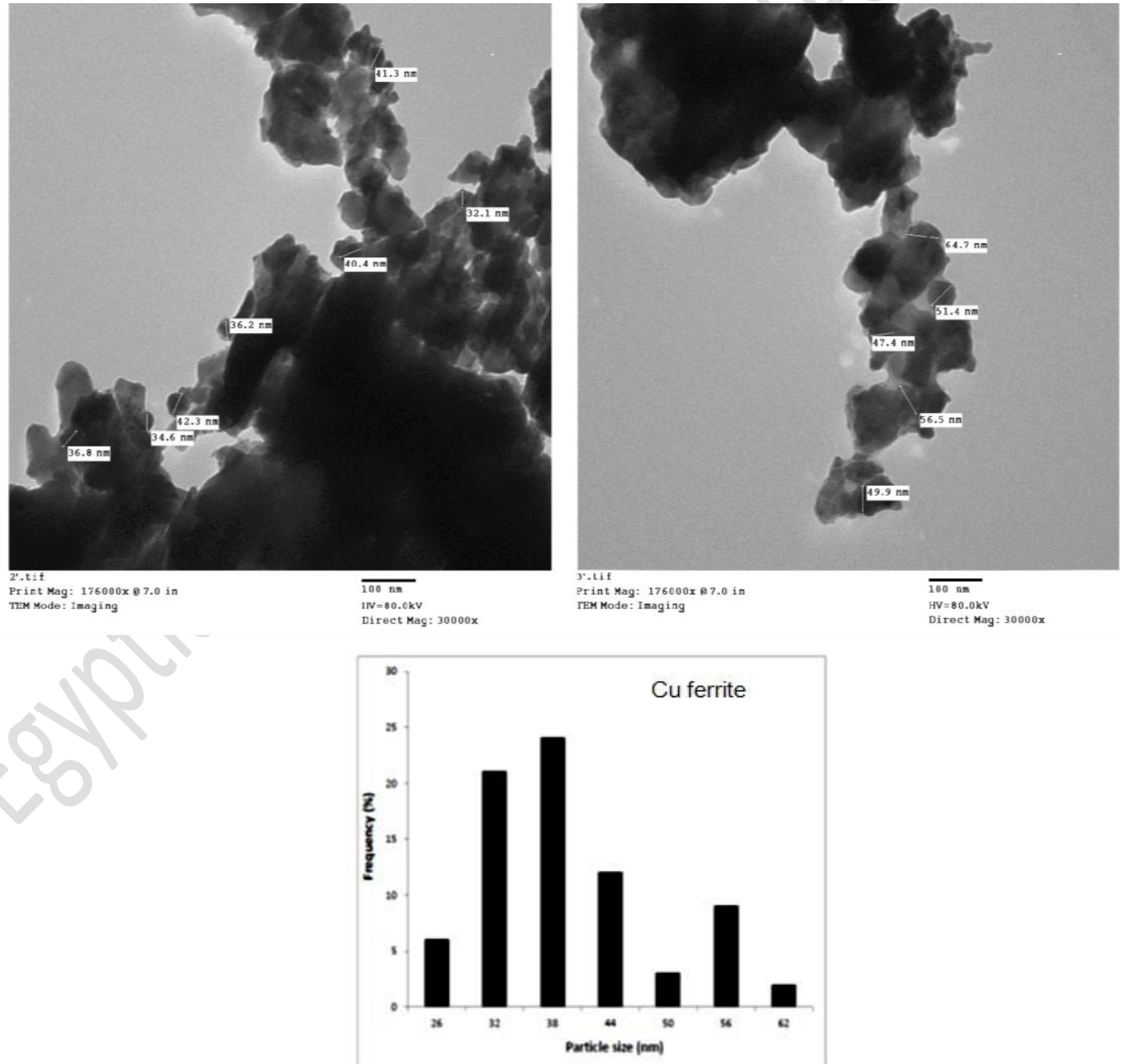

Fig. (3) (a) TEM micrograph of $\mathrm{CuFe}_{2} \mathrm{O}_{4}$ nanoparticles, (b) Sample's particle size distribution histogram. 

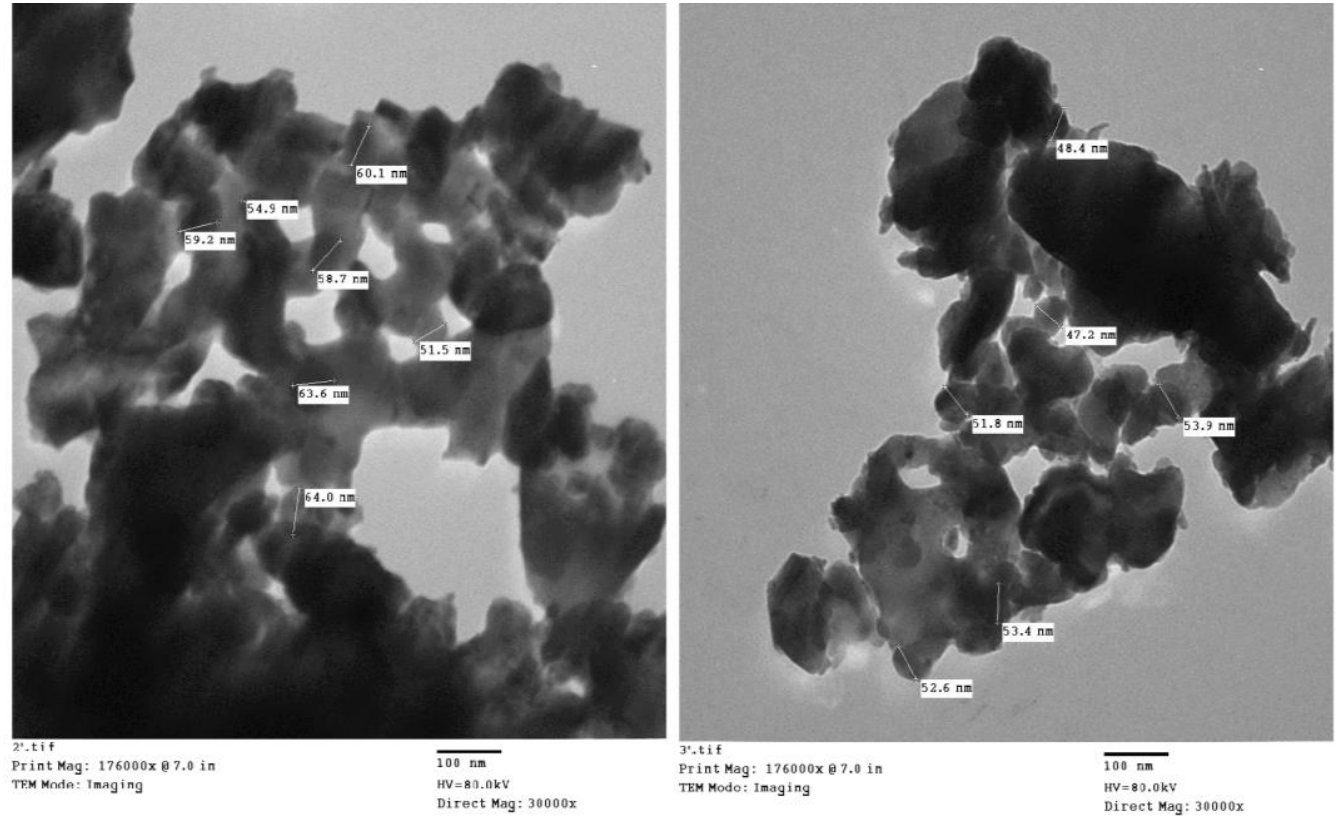

Fig. (4) TEM micrograph of $\mathrm{Cu}_{0.5} \mathrm{Co}_{0.5} \mathrm{Fe}_{2} \mathrm{O}_{4}$ nanoparticles.
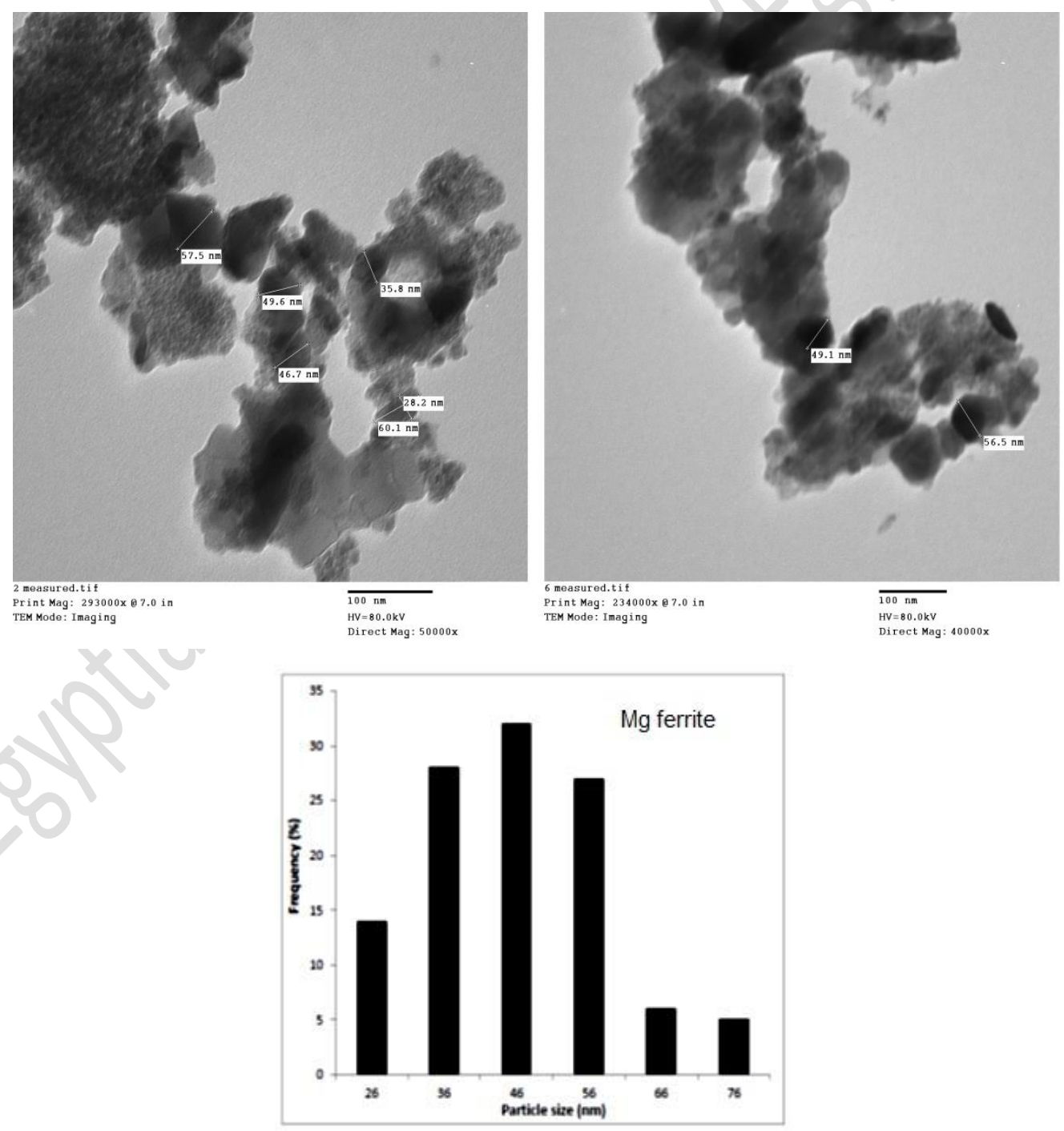

Fig. (5) (a) TEM micrograph of $\mathrm{MgFe}_{2} \mathrm{O}_{4}$ nanoparticles, (b) Sample's particle size distribution histogram. 
The magnetic ions' inter-distances (sometimes called as hopping lengths) in the tetrahedral site $L_{A-A}(\AA)$, the octahedral site $L_{B-B}(\AA)$ and the shared sites $L_{A-B}(\AA)$ have been calculated also by using the XRD data from:

$$
L_{A-A}=\frac{a \sqrt{3}}{4}, \quad L_{B-B}=\frac{a \sqrt{2}}{4} \quad \text { and } \quad L_{A-B}=\frac{a \sqrt{11}}{8}
$$

Table (3): The distances between magnetic ions: $L_{A-A}(\AA), L_{B-B}(\AA)$ and $L_{A-B}(\AA)$.

\begin{tabular}{|l|c|c|c|}
\hline \multicolumn{1}{|c|}{ Sample } & $\mathbf{L}_{\mathbf{A - \mathbf { A }}}(\AA)$ & $\mathbf{L}_{\mathbf{B}-\mathbf{B}}(\AA)$ & $\mathbf{L}_{\mathbf{A}-\mathbf{B}}(\AA)$ \\
\hline $\mathrm{CuFe}_{\mathbf{2}} \mathbf{O}_{\mathbf{4}}$ & 3.620 & 2.956 & 3.466 \\
\hline $\mathrm{CoFe}_{\mathbf{2}} \mathbf{O}_{\mathbf{4}}$ & 3.629 & 2.963 & 3.475 \\
\hline $\mathbf{M g F e}_{\mathbf{2}} \mathbf{O}_{\mathbf{4}}$ & 3.629 & 2.963 & 3.474 \\
\hline $\mathbf{C o}_{\mathbf{0 . 5}} \mathbf{C u}_{\mathbf{0 . 5}} \mathbf{F e}_{\mathbf{2}} \mathbf{O}_{\mathbf{4}}$ & 3.622 & 2.958 & 3.468 \\
\hline
\end{tabular}

It can be observed that the very small changes in the three hopping lengths follow the slight changes in the lattice parameter (a) in consistency with the previous equations.

\subsection{DSC and TGA}

To investigate the thermal dissolution behavior of the samples, TGA and DSC have been used; the thermograms are shown in Fig. (6): (a) and (b) respectively. The TGA of the as-prepared ferrite samples reveals a total weight loss of $3.77 \%, 10.1 \%, 5.47 \%$ and $4.69 \%$ for the $\mathrm{Cu}$ ferrite, $\mathrm{Mg}$ ferrite, Co ferrite and CuCo ferrite respectively. These weight losses have occurred in two or -at most- three steps when the as prepared powders have been heated from $30^{\circ} \mathrm{C}$ to $995^{\circ} \mathrm{C}$ in air. The first weight loss is always attributed to the loss of any absorbed water in the samples. The losses observed in the temperature range $200-500^{\circ} \mathrm{C}$ might be due the evolution of some gases as a result of the decomposition of small remnant amounts of the precursors (nitrates) in the samples such as $\mathrm{NO}_{\mathrm{x}}$ gases, and elimination of some remnant citric acid. The final stage in weight loss at a range of $500-950{ }^{\circ} \mathrm{C}$ is due to the complete formation of the pure ferrites. This has been manifested in the DSC plots as exothermic peaks in the final temperature range [22-24].

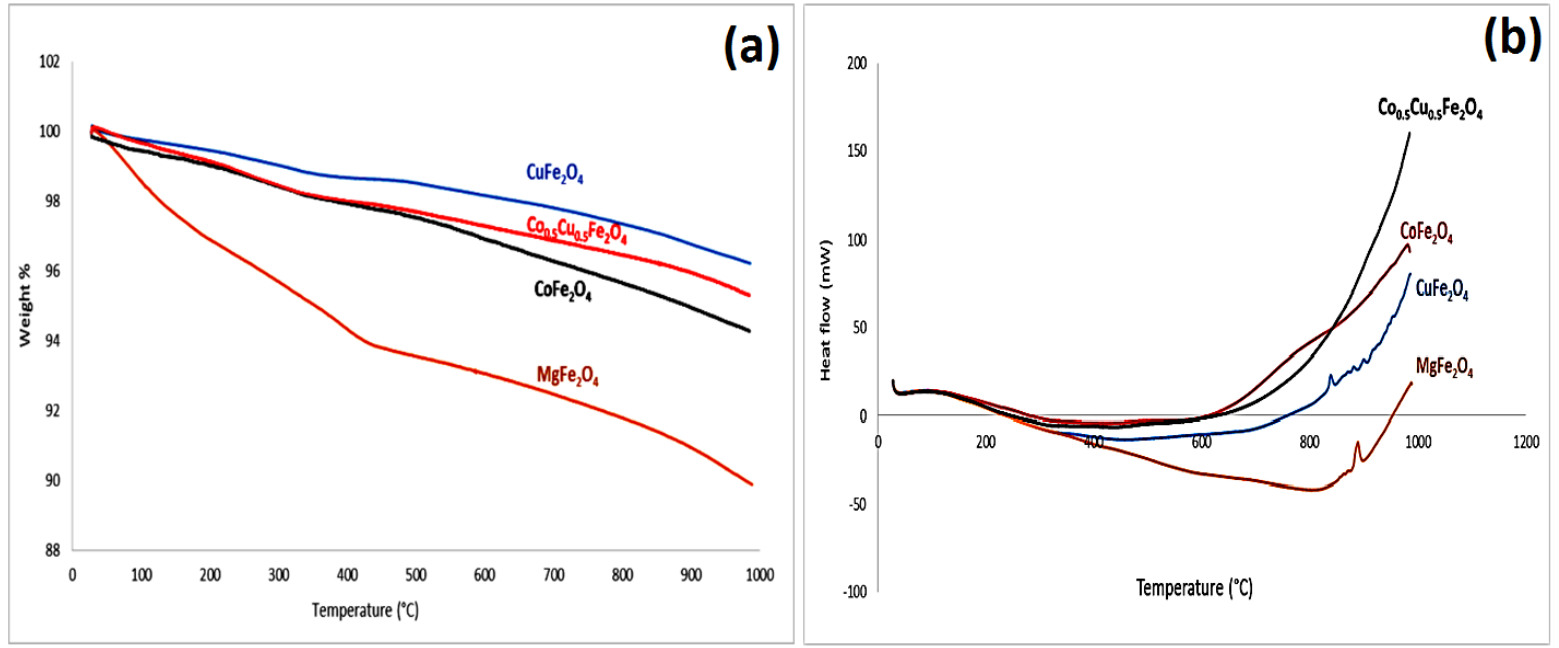

Fig. 6 (a) TGA and (b) DSC thermographs for the ferrite as -prepared systems.

\subsection{FTIR analysis}

Figures 7, 8, 9 and 10 represent the FTIR spectra of the pure polymer PEG and PEG/ferrite nanocomposites. Remembering the chemical formula of PEG which is $\mathrm{H}-\left(\mathrm{O}-\mathrm{CH}_{2}-\mathrm{CH}_{2}\right)_{\mathrm{n}}-\mathrm{OH}$, we can see that the bands characterizing the PEG are observed: At around $1000-1030 \mathrm{~cm}^{-1}$, they represent the $\mathrm{C}-\mathrm{O}$ group vibration modes. Whereas, bands around $1150 \mathrm{~cm}^{-1}$ represent $\mathrm{C}-\mathrm{O}-\mathrm{H}$ groups and around $1200 \mathrm{~cm}^{-1}$ correspond to the plane 
deformation of $\mathrm{C}-\mathrm{H}$ group bending vibrations. Whereas, around $1400 \mathrm{~cm}^{-1}$ the bands represent $\mathrm{C}-\mathrm{O}-\mathrm{H}$ bending modes. The bands at around $1470 \mathrm{~cm}^{-1}$ are due to the stretching vibration of $\mathrm{C}-\mathrm{O}$ in $\mathrm{PEG}[25,26]$.

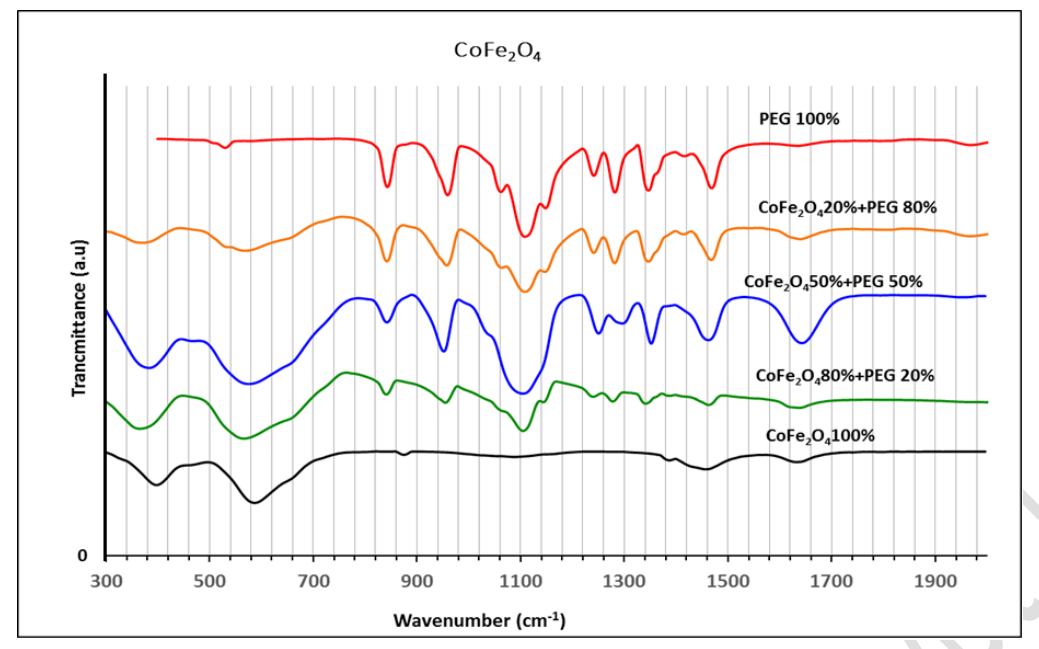

Fig. 7 FTIR spectra of PEG and PEG/CoFe $\mathrm{O}_{4}$ composites

Moreover, the two main bands characterizing the spinel ferrites are also obviously seen in the four figures. $v_{1}$ and $v_{2}$ are in the range around 600 and $400 \mathrm{~cm}^{-1}$, respectively. The $v_{1}$ antipeak which occurs at a higher wave number than $v_{2}$, is attributed to stretching vibrations of tetrahedral (A-site) metal-oxygen bonding. Whereas, the lower frequency anti-peak $v_{2}$ is attributed to the metal-oxygen bonding in the octahedral B-sites [27].

The $v_{1}$ wavenumber values are higher than those of $v_{2}$ due to the shorter bond length at tetrahedral sites than those existent in octahedral sites [28]. These two bands are essential features in all FTIR spectra of ferrites found in literature. The obtained FTIR data for the investigated samples are reported in Table (4). The triple band around $1600 \mathrm{~cm}^{-1}$ is attributed to the stretching modes and hydroxyl groups $\mathrm{H}-\mathrm{O}-\mathrm{H}$ bending vibration, [29]. Finally, the broad band observed at $1420-1450 \mathrm{~cm}^{-1}$, can be attributed to the existing water which is assigned to the vibration of $\mathrm{H}-\mathrm{O}-\mathrm{H}$ group.

Table (4): FTIR main bands of the ferrites and composites (50\% ferrite:50\% PEG).

\begin{tabular}{|l|c|c|l|c|c|}
\hline \multicolumn{1}{|c|}{ Sample } & $\boldsymbol{v}_{\mathbf{1}}\left(\mathrm{cm}^{-1}\right)$ & $\boldsymbol{v}_{\mathbf{2}}\left(\mathrm{cm}^{-1}\right)$ & \multicolumn{1}{c|}{ Composites } & $\boldsymbol{v}_{\mathbf{1}}\left(\mathrm{cm}^{-1}\right)$ & $\boldsymbol{v}_{\mathbf{2}}\left(\mathrm{cm}^{-1}\right)$ \\
\hline $\mathrm{CoFe}_{2} \mathbf{O}_{\mathbf{4}}$ & 587 & 397 & $50 \% \mathrm{CoFe}_{2} \mathrm{O}_{4}: 50 \%$ PEG & 574 & 383 \\
\hline $\mathbf{C u F e}_{2} \mathbf{O}_{\mathbf{4}}$ & 578 & 407 & $50 \% \mathrm{CuFe}_{2} \mathrm{O}_{4}: 50 \%$ PEG & 572 & 405 \\
\hline $\mathrm{CoCuFe}_{2} \mathrm{O}_{\mathbf{4}}$ & 591 & 404 & $50 \% \mathrm{CoCuFe}_{2} \mathrm{O}_{4}: 50 \%$ PEG & 582 & 389 \\
\hline $\mathrm{MgFe}_{\mathbf{2}} \mathrm{O}_{\mathbf{4}}$ & 576 & 434 & $50 \% \mathrm{MgFe}_{2} \mathrm{O}_{4}: 50 \%$ PEG & 555 & 437 \\
\hline
\end{tabular}

It can be obviously noticed the existence of a systematic shift of the main bands of ferrites $v_{1}$ and $v_{2}$ upon introducing the polymer with the ferrites forming the composites. This can be attributed to the formation of hydrogen bonding between some of the oxygen atoms partially involved in covalent bonding in the ferrites - despite that the ferrites are mainly ionic bonded compounds- and the $\mathrm{OH}$ group in the polymer [17]. 


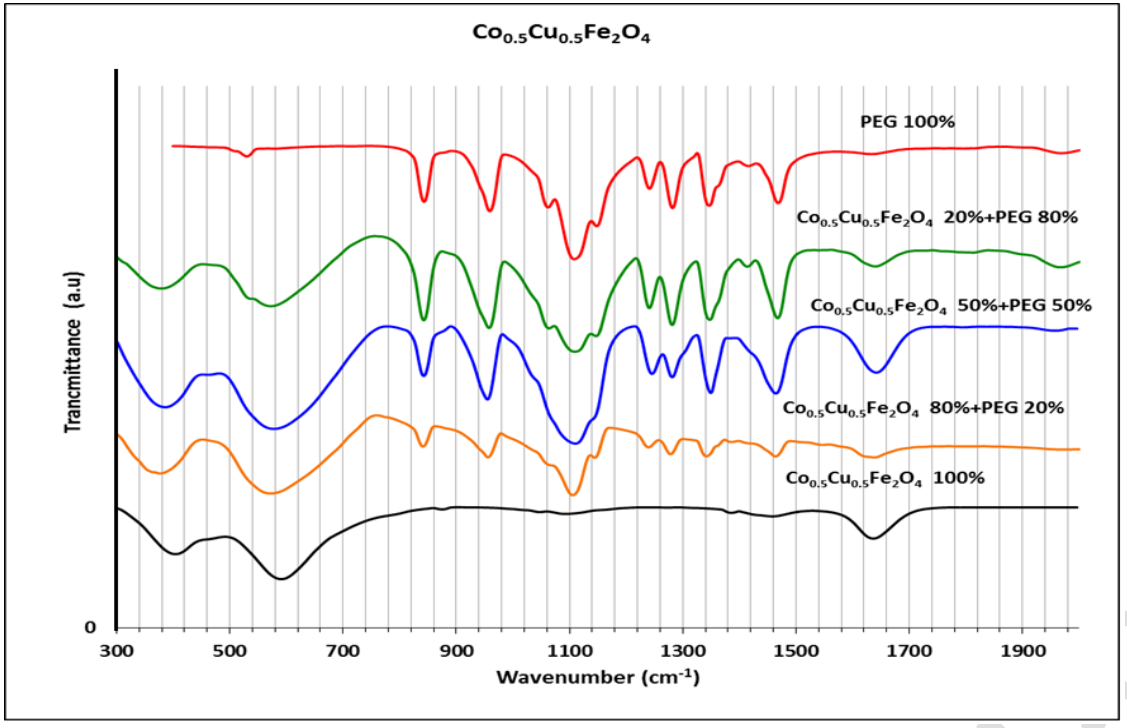

Fig. 8: FTIR spectra of PEG and PEG/ $\mathrm{Co}_{0.5} \mathrm{Cu}_{0.5} \mathrm{Fe}_{2} \mathrm{O}_{4}$ composites.

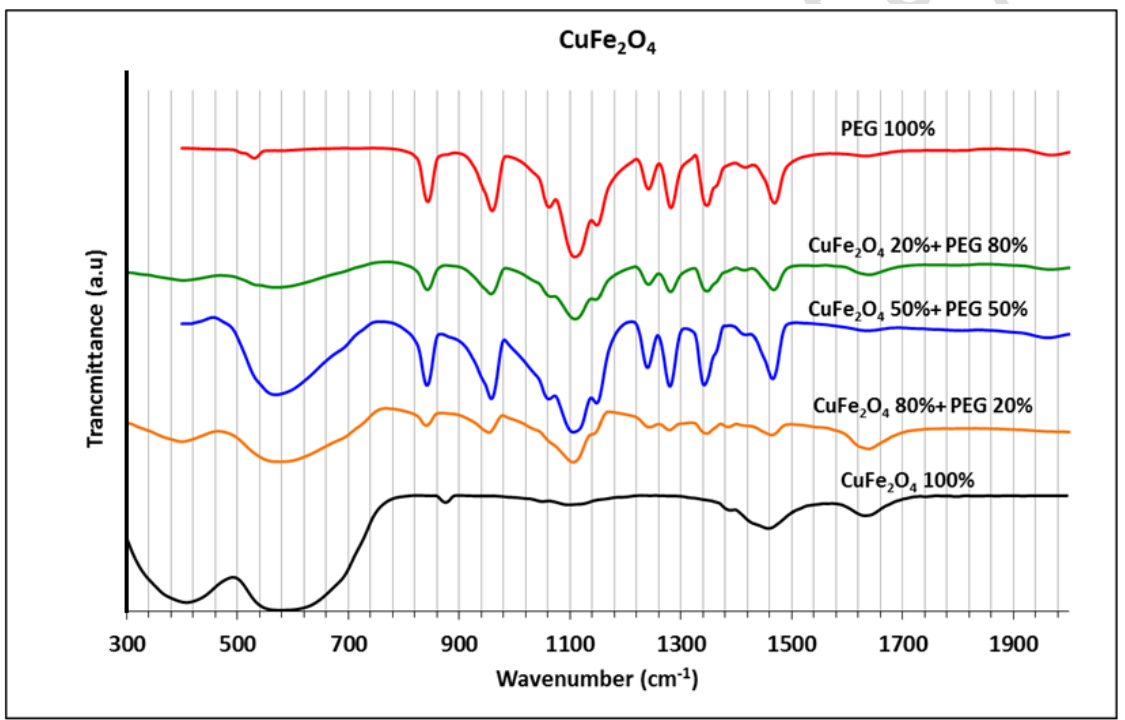

Fig. 9: FTIR spectra of PEG and PEG/CuFe $\mathrm{O}_{4}$ composites. 


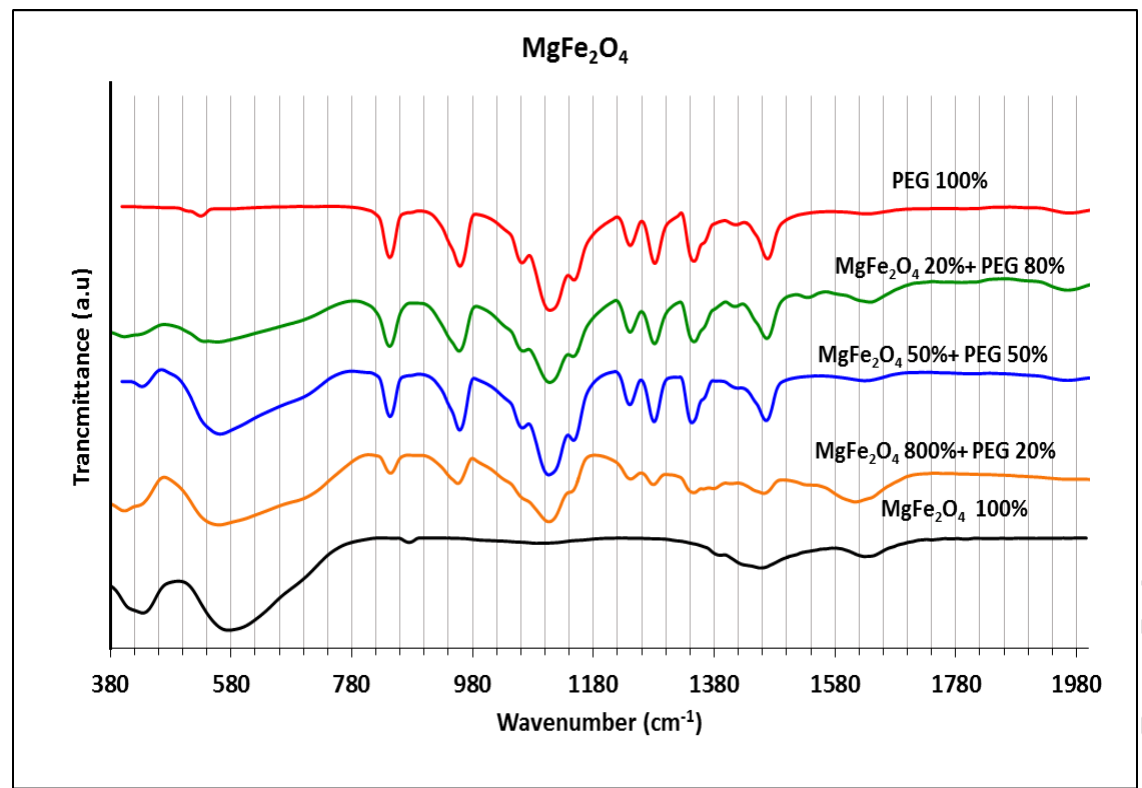

Fig. 10: FTIR spectra of PEG and PEG/MgFe $\mathrm{O}_{4}$ composites.

\section{4 (VSM) Magnetic Measurements}

The magnetic hysteresis loops of all the samples have been measured at room temperature using vibrating sample magnetometer (VSM) for both ferrites and composite samples. As shown in Fig. 11, the obtained results for the pure ferrite samples are in a good agreement with the expected values [30,31].

The Co-ferrite has the highest values of $M_{s}$ (the saturation magnetization), $M_{r}$ ( the remnant magnetization) and $\mathrm{H}_{\mathrm{c}}$ (the coercive field). This is due to the higher net moments of $\mathrm{Co}$ ions than $\mathrm{Mg}$ and $\mathrm{Cu}$ ions. After the Co-ferrite, the $\mathrm{Co}_{0.5} \mathrm{Cu}_{0.5}$ ferrite has come in the second place concerning the values of $\mathrm{M}_{\mathrm{s}}, \mathrm{M}_{\mathrm{r}}$ and $\mathrm{H}_{\mathrm{c}}$. The $\mathrm{Cu}$ ferrite is in the third place and finally the $\mathrm{Mg}$ ferrite is having the smallest values as shown in Table 5. 


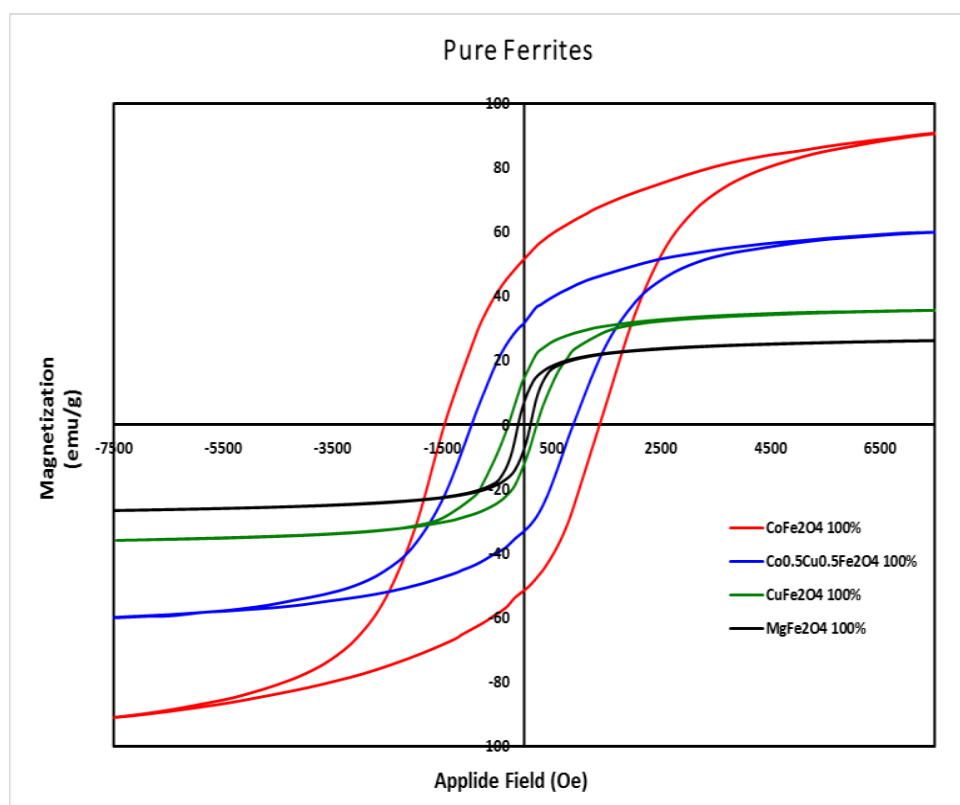

Fig. 11: Magnetic Hysteresis loops of the pure ferrites.

Table 5: The VSM parameter for pure ferrites samples.

\begin{tabular}{|l|c|c|c|c|}
\hline \multicolumn{1}{|c|}{ Sample } & $\mathbf{M}_{\mathbf{s}}(\mathrm{emu} / \mathrm{g})$ & $\mathbf{M}_{\mathbf{r}}(\mathrm{emu} / \mathrm{g})$ & $\mathbf{H}_{\mathrm{c}}(\mathrm{Oe})$ & $\mathbf{R}=\mathbf{M}_{\mathbf{r}} / \mathbf{M}_{\mathbf{s}}$ \\
\hline $\mathbf{C o F e}_{\mathbf{2}} \mathbf{O}_{\mathbf{4}}$ & 91.23 & 51.01 & 1460 & 0.56 \\
\hline $\mathbf{C o}_{\mathbf{0 . 5}} \mathbf{C u}_{\mathbf{0 . 5}} \mathbf{F e}_{\mathbf{2}} \mathbf{O}_{\mathbf{4}}$ & 59.88 & 31.55 & 870 & 0.53 \\
\hline $\mathbf{C u F e}_{\mathbf{2}} \mathbf{O}_{\mathbf{4}}$ & 35.76 & 13.51 & 340 & 0.38 \\
\hline $\mathbf{M g F e}_{\mathbf{2}} \mathbf{O}_{\mathbf{4}}$ & 26.24 & 4.9 & 233 & 0.19 \\
\hline
\end{tabular}

Moreover, the cation distribution of metal ions, between A and B sites has a great effect on the magnetic properties since it affects the net moment and the total A-B super-exchange interaction. Therefore, the cation distribution has been calculated as follows:

The magnetic moment $\mu_{\mathrm{B}}$ can be computed from:

$$
\mu_{B}=\frac{M_{A} M_{S}}{N_{A} \beta}
$$

; where $M_{s}$ is the saturation magnetization, $N_{A}$ is Avogadro's number, $M_{A}$ is the molecular weight and $\beta$ is a factor to convert the magnetic moment per atom in Bohr magnetons $\left(\beta=9.27 \times 10^{-21} \mathrm{erg} /\right.$ gauss $)$ [32].

Then, a hypothetical cation distribution has been assumed to give net magnetic moments conforming to the moments calculated from the above equation.

The assumed cation distributions of the form : $\left(M e_{\delta}^{2+} F e_{1-\delta}^{3+}\right)^{A}\left[M e_{1-\delta}^{2+} F e_{1+\delta}^{3+}\right]^{B} \mathrm{O}_{4}$ based on the published site predilection of the ions along with the values of the magnetic moments (experimental) $\mu_{B}$ are shown in Table 6 . Therefore, according to the above proposed cation distribution, our samples have partially inverse spinel structure. The cation distribution may serve significantly in the interpretation of electrical behaviour of the samples in a soon future study. 
Table 6: The measured magnetic moment $\mathrm{m}_{\mathrm{exp}}$ and the cation distributions of the pure ferrite.

\begin{tabular}{|l|c|c|}
\hline \multicolumn{1}{|c|}{ Sample } & $\mathbf{m}_{\text {exp }}\left(\boldsymbol{\mu}_{\boldsymbol{B}}\right)$ & The proposed cation distribution according to $\mathbf{m}_{\text {exp }}$ \\
\hline $\mathbf{C o F e}_{\mathbf{2}} \mathbf{O}_{\mathbf{4}}$ & 3.833 & $\left(\mathrm{Co}_{0.227} \mathrm{Fe}_{0.772}\right)\left[\mathrm{Co}_{0.772} \mathrm{Fe}_{1.227}\right] \mathrm{O}_{4}$ \\
\hline $\mathbf{C o C u F e}_{2} \mathbf{O}_{\mathbf{4}}$ & 2.384 & $\left(\mathrm{Co}_{0.063} \mathrm{Cu}_{0.028} \mathrm{Fe}_{0.908}\right)\left[\mathrm{Co}_{0.436} \mathrm{Cu}_{0.471} \mathrm{Fe}_{1.091}\right] \mathrm{O}_{4}$ \\
\hline $\mathbf{M g F e}_{\mathbf{2}} \mathbf{O}_{\mathbf{4}}$ & 0.823 & $\left(\mathrm{Mg}_{0.0823} \mathrm{Fe}_{0.917}\right)\left[\mathrm{Mg}_{0.917} \mathrm{Fe}_{1.082}\right] \mathrm{O}_{4}$ \\
\hline $\mathbf{C u F e}_{\mathbf{2}} \mathbf{O}_{\mathbf{4}}$ & 1.358 & $\left(\mathrm{Cu}_{0.0447} \mathrm{Fe}_{0.955}\right)\left[\mathrm{Cu}_{0.955} \mathrm{Fe}_{1.045}\right] \mathrm{O}_{4}$ \\
\hline
\end{tabular}

In the copper ferrite sample, the existence of the $\mathrm{Cu}^{2+}$ ion in the nanocrystals may cause a lattice distortion (Jahn-Teller effect), which may modify the magnetic properties too.

Figures 12, 13, 14 and 15 illustrate the hysteresis loops of the PEG/MFe $\mathrm{O}_{4}$ ferrite nanocomposites, where $\mathrm{M}$ stands for $\mathrm{Co}, \mathrm{Co}_{0.5} \mathrm{Cu}_{0.5}, \mathrm{Cu}$ and $\mathrm{Mg}$ respectively. The same trend of hysteresis loops of the pure ferrites is observed in the $\mathrm{PEG} / \mathrm{MFe}_{2} \mathrm{O}_{4}$ nanocomposites samples, but with smaller values of $\mathrm{M}_{\mathrm{s}}$ and $\mathrm{M}_{\mathrm{r}}$. Whereas, $\mathrm{H}_{\mathrm{c}}$ values remain constant as obtained in pure ferrites. For a constant distribution of particle sizes such as in our samples, this is logical because $\mathrm{H}_{\mathrm{c}}$ may vary with large variations in particle sizes only, but in our case the same prepared ferrite sample has been used to prepare the three corresponding composite samples with different ratios. Both $\mathrm{M}_{\mathrm{s}}$ and $\mathrm{M}_{\mathrm{r}}$ have linear decrease proportional to the increase of PEG in the measured sample. This is due to the decrease of magnetic domains and consequently lowering the number of total spin moments which contribute to the values of $\mathrm{M}_{\mathrm{s}}$ and $\mathrm{M}_{\mathrm{r}}$. In other words, PEG is considered as non-magnetic regions separating the magnetic ferrite nano-crystals thereby decreasing the resultant $\mathrm{M}_{\mathrm{s}}$ and $\mathrm{M}_{\mathrm{r}}$ of the composites [33].

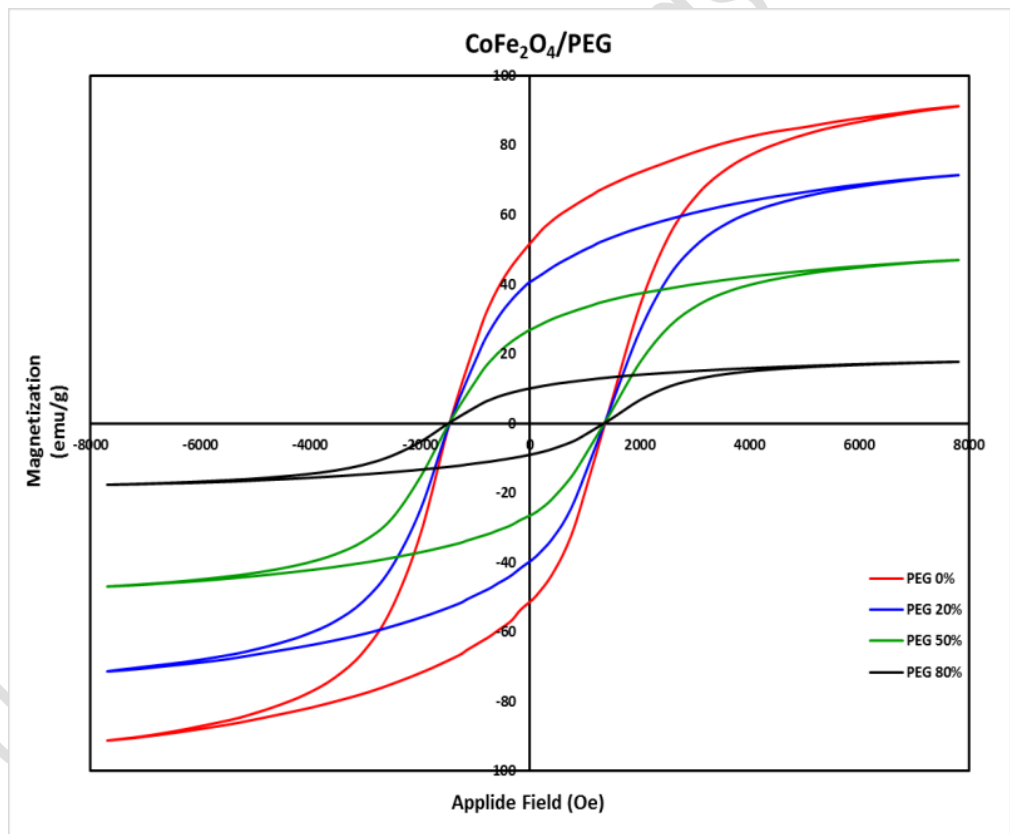

Fig.12: Magnetic Hysteresis loops of $\mathrm{PEG} / \mathrm{CoFe}_{2} \mathrm{O}_{4}$ composites.

Table 7: The VSM parameter for $\mathrm{CoFe}_{2} \mathrm{O}_{4} / \mathrm{PEG}$ samples.

\begin{tabular}{|l|c|c|c|c|}
\hline \multicolumn{1}{|c|}{ Sample } & $\mathbf{M}_{\mathbf{s}}(\mathrm{emu} / \mathrm{g})$ & $\mathbf{M}_{\mathrm{r}}(\mathrm{emu} / \mathrm{g})$ & $\mathbf{H}_{\mathrm{c}}(\mathrm{Oe})$ & $\mathbf{R}=\mathbf{M}_{\mathrm{r}} / \mathbf{M}_{\mathbf{s}}$ \\
\hline Co+ PEG 0\% & 91.23 & 51.01 & 1460 & 0.56 \\
\hline PEG 20\% & 71.24 & 40.24 & 1460 & 0.56 \\
\hline PEG 50\% & 46.92 & 26.54 & 1460 & 0.57 \\
\hline PEG 80\% & 17.69 & 9.93 & 1460 & 0.56 \\
\hline
\end{tabular}

Returning to Figure 12 which shows the $\mathrm{CoFe}_{2} \mathrm{O}_{4} / \mathrm{PEG}$ composites magnetic hysteresis loops at different concentration of PEG. 
The data obtained from this figure have been listed in the table 7 from this table we can conclude as mentioned above that the $H_{c}$ values remain constant while both $M_{s}$ and $M_{r}$ decrease with increasing PEG concentrations. The squareness values $R=M_{r} / M_{s}$ are around 0.5 which refers to uniaxial anisotropy of the samples [34].

The PEG/CoFe $\mathrm{O}_{4}$ nanocomposites have bulk-like coercive field at room temperature which may be suitable for some applications.

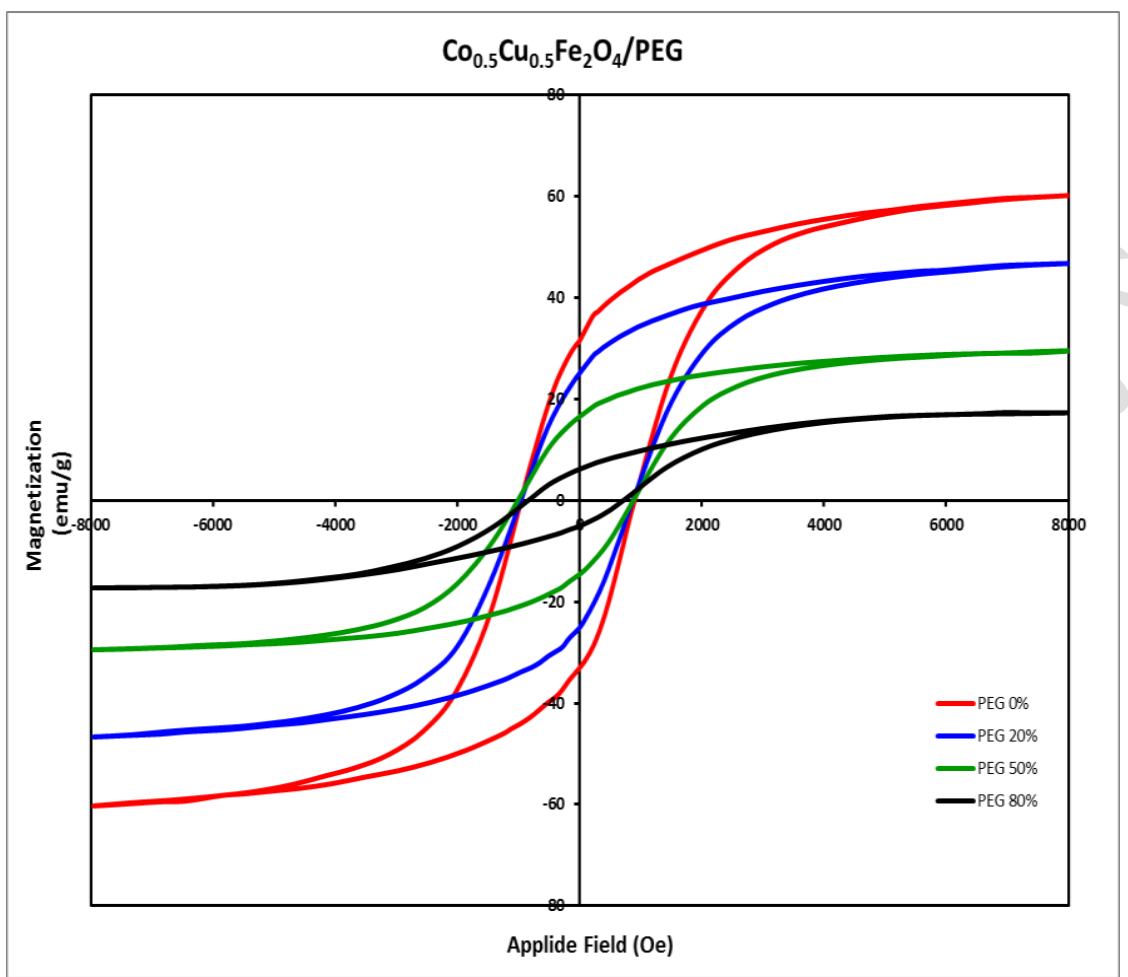

Fig.13: Magnetic Hysteresis loops of $\mathrm{PEG} / \mathrm{Co}_{0.5} \mathrm{Cu}_{0.5} \mathrm{Fe}_{2} \mathrm{O}_{4}$ composites.

Table 8: The VSM parameter for $\mathrm{Co}_{0.5} \mathrm{Cu}_{0.5} \mathrm{Fe}_{2} \mathrm{O}_{4} / \mathrm{PEG}$ samples.

\begin{tabular}{|l|c|c|c|c|}
\hline \multicolumn{1}{|c|}{ Sample } & $\mathbf{M}_{\mathbf{s}}(\mathrm{emu} / \mathrm{g})$ & $\mathbf{M}_{\mathbf{r}}(\mathrm{emu} / \mathrm{g})$ & $\mathbf{H}_{\mathbf{c}}(\mathrm{Oe})$ & $\mathbf{R}=\mathbf{M}_{\mathbf{r}} / \mathbf{M}_{\mathbf{s}}$ \\
\hline $\mathbf{C o}_{\mathbf{0 . 5}} \mathbf{C u}_{\mathbf{0 . 5}}+$ PEG 0\% & 60.24 & 31.55 & 820 & 0.52 \\
\hline PEG 20\% & 46.72 & 25.53 & 820 & 0.55 \\
\hline PEG 50\% & 29.52 & 16.68 & 820 & 0.57 \\
\hline PEG 80\% & 17.28 & 6.34 & 820 & 0.37 \\
\hline
\end{tabular}

The $\mathrm{Co}_{0.5} \mathrm{Cu}_{0.5} \mathrm{Fe}_{2} \mathrm{O}_{4} / \mathrm{PEG}$ samples also show hysteresis loops of hard magnetic nature; where the $\mathrm{Cu}, \mathrm{Co}$ and $\mathrm{Fe}$ cations occupy the interstitial sites $\mathrm{A}$ and $\mathrm{B}$ as mentioned above in the proposed cation distribution. Again, the algebraic sum of the magnetic moments of both sublattices gives the net magnetization. The tabulated data shows that the saturation magnetization values of the $\mathrm{Co}_{0.5} \mathrm{Cu}_{0.5} \mathrm{Fe}_{2} \mathrm{O}_{4} / \mathrm{PEG}$ nano-composites are less than those obtained for $\mathrm{CoFe}_{2} \mathrm{O}_{4} / \mathrm{PEG}$ nanocomposites but greater than those of $\mathrm{CuFe}_{2} \mathrm{O}_{4} / \mathrm{PEG}$ composites. The reduction of $\mathrm{M}_{\mathrm{s}}$ for $\mathrm{Co}_{0.5} \mathrm{Cu}_{0.5} \mathrm{Fe}_{2} \mathrm{O}_{4} / \mathrm{PEG}$ samples compared to $\mathrm{CoFe}_{2} \mathrm{O}_{4}$ can be easily attributed to the decrease of the number of magnetic Co ions. The squareness values $\mathrm{R}=\mathrm{M}_{\mathrm{r}} / \mathrm{M}_{\mathrm{s}}$ are around 0.5 too, which refers to uniaxial anisotropy of the samples with one exception of the last $80 \%$ PEG composite. 


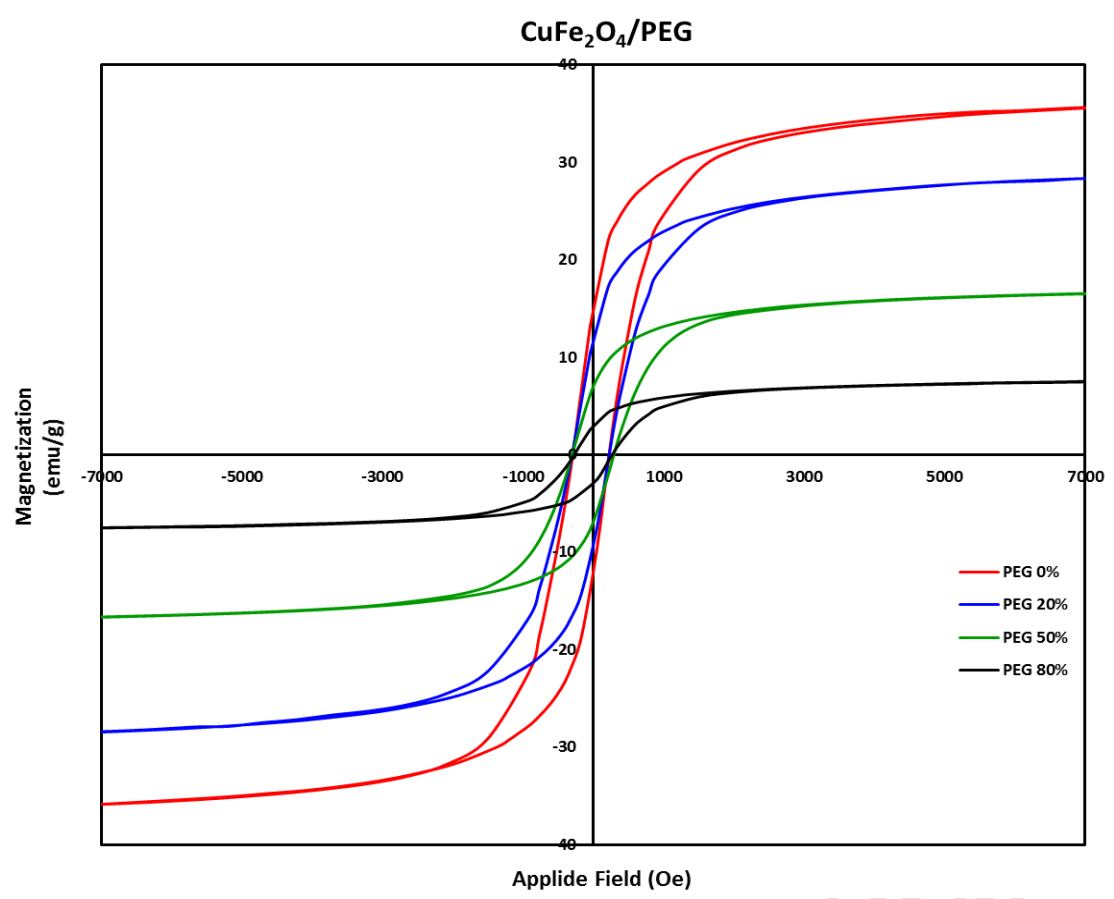

Fig.14: Magnetic Hysteresis loops of $\mathrm{PEG} / \mathrm{CuFe}_{2} \mathrm{O}_{4}$ composites.

Table 9: The VSM parameter for $\mathrm{CuFe}_{2} \mathrm{O}_{4} / \mathrm{PEG}$ samples.

\begin{tabular}{|l|c|c|c|c|}
\hline \multicolumn{1}{|c|}{ Sample } & $\mathbf{M}_{\mathbf{s}}(\mathrm{emu} / \mathrm{g})$ & $\mathbf{M}_{\mathbf{r}}(\mathrm{emu} / \mathrm{g})$ & $\mathbf{H}_{\mathrm{c}}(\mathrm{Oe})$ & $\mathbf{R}=\mathbf{M}_{\mathbf{r}} / \mathbf{M}_{\mathbf{s}}$ \\
\hline Cu+ PEG 0\% & 35.75 & 13.25 & 340 & 0.37 \\
\hline PEG 20\% & 28.28 & 10.37 & 340 & 0.37 \\
\hline PEG 50\% & 16.51 & 6.74 & 340 & 0.41 \\
\hline PEG 80\% & 7.5 & 2.56 & 340 & 0.34 \\
\hline
\end{tabular}

The data of $\mathrm{CuFe}_{2} \mathrm{O}_{4}$ and $\mathrm{CuFe}_{2} \mathrm{O}_{4} / \mathrm{PEG}$ samples in Figure 14 show soft magnetic behavior at room temperature, making these materials favorable for high frequency applications [34].

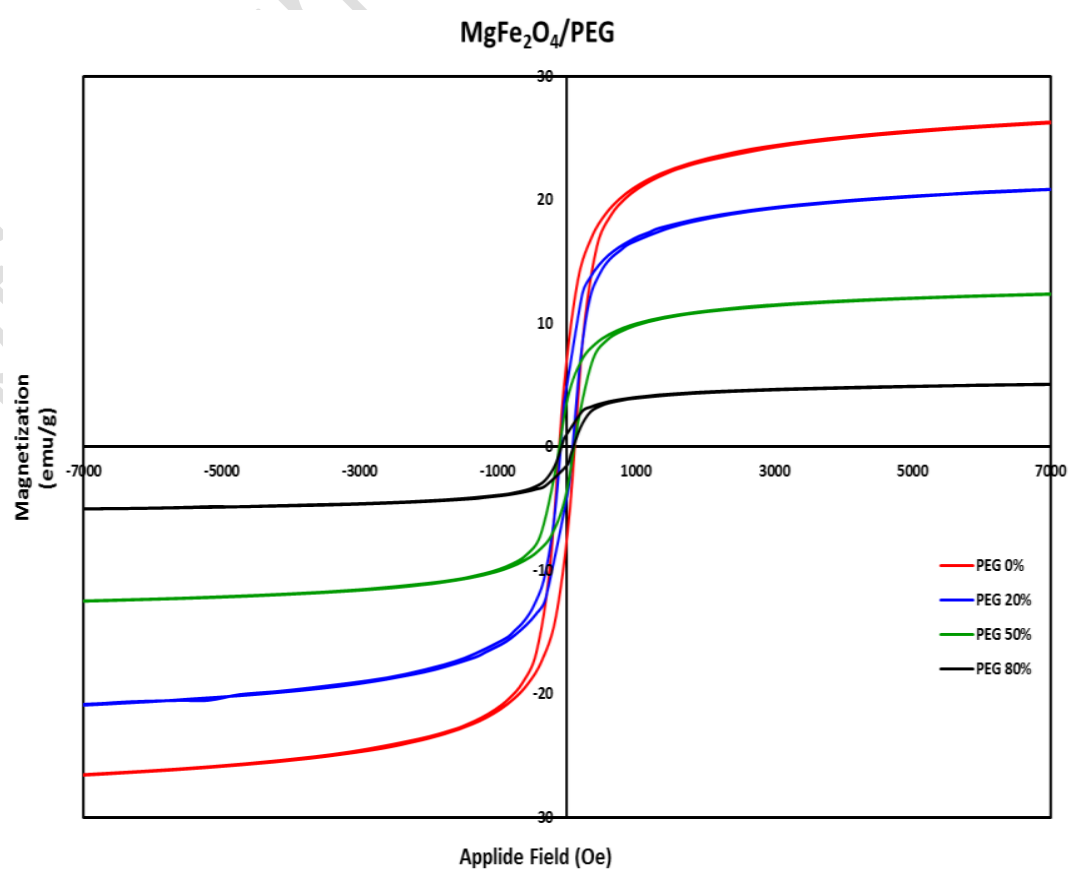

Fig.15: Magnetic Hysteresis loops of $\mathrm{PEG} / \mathrm{MgFe}_{2} \mathrm{O}_{4}$ composites. 
Table 10: The VSM parameter for $\mathrm{MgFe}_{2} \mathrm{O}_{4} / \mathrm{PEG}$ samples.

\begin{tabular}{|l|c|c|c|c|}
\hline \multicolumn{1}{|c|}{ Sample } & $\mathbf{M}_{\mathbf{s}}(\mathrm{emu} / \mathrm{g})$ & $\mathbf{M}_{\mathbf{r}}(\mathrm{emu} / \mathrm{g})$ & $\mathbf{H}_{\mathbf{c}}(\mathrm{Oe})$ & $\mathbf{R}=\mathbf{M}_{\mathbf{r}} / \mathbf{M}_{\mathbf{s}}$ \\
\hline Mg+PEG 0\% & 26.24 & 4.92 & 233 & 0.19 \\
\hline PEG 20\% & 20.79 & 3.69 & 233 & 0.18 \\
\hline PEG 50\% & 12.31 & 2.48 & 233 & 0.20 \\
\hline PEG 80\% & 4.99 & 0.68 & 233 & 0.14 \\
\hline
\end{tabular}

The data of $\mathrm{MgFe}_{2} \mathrm{O}_{4}$ and $\mathrm{MgFe}_{2} \mathrm{O}_{4} / \mathrm{PEG}$ samples in Figure 15 show super-paramagnetic behavior. Such behavior may make these materials beneficial for wide range of applications such as drug delivery, bio-separation and magnetic refrigeration systems.

In other words, regarding the composite samples, it can be observed that when the PEG has been introduced, the saturation magnetization $M_{s}$ values have decreased compared to the pure ferrite samples although the same trend of the hysteresis loops has been maintained. This is fairly expected and attributed of course to the decrease of magnetic domains and the degree of spin alignment with the applied field in the composite because the large molecules of PEG represent non-magnetic regions separating magnetic domains of the ferrites. Regarding the values of $\mathrm{M}_{\mathrm{r}}$ and $\mathrm{H}_{\mathrm{c}}$ displayed in the data tables, however, they are worth reported in order to nominate the material later for a particular application. For example, it is worth noting that the samples of $\mathrm{Cu}$ ferrite and $\mathrm{Cu}$ ferrite/PEG composite may serve in typical electromagnetic interference suppressors. This suggestion may be confirmed by investigating our $\mathrm{H}_{c}$ values, where it had been stated in the literature [35] that " $\mathrm{H}_{c}$ value lying in the range of few hundred Oe is a necessary condition for EMI suppressing fabrics".

\section{Conclusion}

The preparation of $\mathrm{CoFe}_{2} \mathrm{O}_{4}, \mathrm{CuFe}_{2} \mathrm{O}_{4}, \mathrm{Co}_{0.5} \mathrm{Cu}_{0.5} \mathrm{Fe}_{2} \mathrm{O}_{4}$ and $\mathrm{MgFe}_{2} \mathrm{O}_{4}$ ferrite nanoparticles $\mathrm{CoFe}_{2} \mathrm{O}_{4}, \mathrm{CuFe}_{2} \mathrm{O}_{4}, \mathrm{Co}_{0.5} \mathrm{Cu}_{0.5} \mathrm{Fe}_{2} \mathrm{O}_{4}$ and $\mathrm{MgFe}_{2} \mathrm{O}_{4}$ ferrite nano-particles has been successful by using the citrate precursor combustion method. No undesired phases are found in the samples.

The main bands of ferrites and also those of the polymer have been clearly displayed by FTIR analysis. A systematic shift of the bands has been observed upon adding PEG and has been attributed to the formation of hydrogen bonds between some of the oxygen atoms partially involved in covalent bonding in the ferrites and the $\mathrm{OH}$ group in the polymer.

TGA and DSC thermographs of the ferrite samples have ensured the complete formation of pure ferrites at temperatures above $800^{\circ} \mathrm{C}$.

The saturation magnetization of the Co ferrite sample is the highest among the four ferrite samples. The saturation magnetization of the composites containing PEG along with the ferrites is lowered as expected.

All samples can be considered as soft magnetic materials and have displayed $\mathrm{H}_{\mathrm{c}}$ values which suggest that they may be useful in electromagnetic wave attenuation according to literature.

An assumed cation distribution of the pure ferrite samples according to the calculated experimental magnetic moment $\mu_{\exp }$ has revealed that the ferrite samples have partially inverse spinel structure.

\section{References:}

[1] S.A. Habib, S.A. Saafan, T.M. Meaz, H.A. Motaweh, P. Knoll, A new method for the preparation of cobalt nanoferrite / graphene composite, (2021) 1-15.

[2] S. V Trukhanov, A. V Trukhanov, V.G. Kostishyn, L. V Panina, A. V Trukhanov, V.A. Turchenko, D.I. Tishkevich, E.L. Trukhanova, O.S. Yakovenko, L.Y. Matzui, D.A. Vinnik, Effect of gallium doping on ectromagnetic properties of barium hexaferrite, J. Phys. Chem. Solids. (2017). 
https://doi.org/10.1016/j.jpcs.2017.07.014.

[3] M. Ounacer, A. Essoumhi, M. Sajieddine, A. Razouk, A. Fnidiki, F. Richomme, J. Juraszek, S.M. Dubiel, M. Sahlaoui, Substitutional effect of $\mathrm{Mg} 2+$ on structural and magnetic properties of cobalt nanoferrite, J. Phys. Chem. Solids. 148 (2021) 109687. https://doi.org/10.1016/j.jpcs.2020.109687.

[4] P. Monisha, P. Priyadharshini, S.S. Gomathi, K. Pushpanathan, Influence of Mn dopant on the crystallite size, optical and magnetic behaviour of CoFe2O4 magnetic nanoparticles, J. Phys. Chem. Solids. 148 (2021) 109654. https://doi.org/10.1016/j.jpcs.2020.109654.

[5] M.A. Hakim, S.K. Nath, S.S. Sikder, K. Hanium Maria, Cation distribution and electromagnetic properties of spinel type Ni-Cd ferrites, J. Phys. Chem. Solids. 74 (2013) 1316-1321. https://doi.org/10.1016/j.jpcs.2013.04.011.

[6] Z. Qi, L. Chunbo, W. Zhuang, Y. Yang, X. Zhiyong, Z. Haikun, C. Chudong, Preparation of rGO/PVA/CIP composites and their microwave absorption properties, J. Magn. Magn. Mater. 479 (2019) 337-343. https://doi.org/10.1016/j.jmmm.2018.11.129.

[7] N.I. Abu-Elsaad, A.S. Nawara, S.A. Mazen, Synthesis, structural characterization, and magnetic properties of $\mathrm{Ni}-\mathrm{Zn}$ nanoferrites substituted with different metal ions (Mn2+, $\mathrm{Co} 2+$, and $\mathrm{Cu} 2+), \mathrm{J}$. Phys. Chem. Solids. 146 (2020) 109620. https://doi.org/10.1016/j.jpcs.2020.109620.

[8] K. Jangam, K. Patil, S. Balgude, S. Patange, P. More, Synthesis and characterization of magnetically separable $\mathrm{Zn} 1-\mathrm{xCoxFeMnO} 4$ nanoferrites as highly efficient photocatalyst for degradation of dye under solar light irradiation, J. Phys. Chem. Solids. 148 (2021) 109700. https://doi.org/10.1016/j.jpcs.2020.109700.

[9] M. Shoba, S. Kaleemulla, Structural, optical and dielectric studies of Er substituted zinc ferrite nanospheres, J. Phys. Chem. Solids. 111 (2017) 447-457. https://doi.org/10.1016/j.jpcs.2017.08.028.

[10] M. V. Kuznetsov, Y.G. Morozov, O. V. Belousova, Synthesis of copper ferrite nanoparticles, Inorg. Mater. 49 (2013) 606-615. https://doi.org/10.1134/S0020168513050063.

[11] R. Köferstein, T. Walther, D. Hesse, S.G. Ebbinghaus, Preparation and characterization of nanosized magnesium ferrite powders by a starch-gel process and corresponding ceramics, J. Mater. Sci. 48 (2013) 6509-6518. https://doi.org/10.1007/s10853-013-7447-x.

[12] M. Anis-Ur-rehman, M.A. Malik, K. Khan, A. Maqsood, Structural, electrical and magnetic properties of nanocrystalline Mg-Co ferrites prepared by co-precipitation, J. Nano Res. 14 (2011) 1-9. https://doi.org/10.4028/www.scientific.net/JNanoR.14.1.

[13] H. Çavuşoğlu, Evaluating the influence of polyethylene glycol as a surfactant on CdO films grown by SILAR method, J. Phys. Chem. Solids. 124 (2019) 67-72. https://doi.org/10.1016/j.jpcs.2018.08.034.

[14] M.A. Ahmed, N. Okasha, N.G. Imam, Crossover Between PEG and BT/NZF Magnetoelectric Nanocomposites for Tailoring Applicable Multiferroic Materials, J. Supercond. Nov. Magn. 28 (2015) 2783-2793. https://doi.org/10.1007/s10948-015-3115-5.

[15] M.A. Ahmed, N. Okasha, S.F. Mansour, S.I. El-dek, Bi-modal improvement of the physico-chemical characteristics of PEG and MFe2O4 subnanoferrite, J. Alloys Compd. 496 (2010) 345-350. https://doi.org/10.1016/j.jallcom.2010.02.009.

[16] R. Topkaya, U. Kurtan, A. Baykal, H. Sözeri, M.S. Toprak, Polymer Assisted Co-precipitation Synthesis and Characterization of Polyethylene Glycol (PEG)/CoFe2O4 Nanocomposite, J. Inorg. Organomet. Polym. Mater. 23 (2013) 592-598. https://doi.org/10.1007/s10904-012-9818-1.

[17] M.M. Hussein, S.A. Saafan, N.A.S. Maha, Polybenzoxazine / Mg - Zn nano - ferrite composites : preparation, identification, and magnetic properties, Appl. Phys. A. (2021). https://doi.org/10.1007/s00339-021-04620-8.

[18] V.D. De Oliveira, R.M. Rubinger, G. Rodrigues, B. Pinheirinho, M. Properties, L = b cos i, 19 (2016) 786-790.

[19] B. Akbari, M.P. Tavandashti, M. Zandrahimi, Particle size characterization of nanoparticles- a practicalapproach, Iran. J. Mater. Sci. Eng. 8 (2011) 48-56.

[20] N. Co, À. Li, S.T. Assar, H.F. Abosheiasha, S.A. Saafan, M.K. El Nimr, Preparation, characterization and magnetization of nano and bulk, J. Mol. Struct. 1084 (2015) 128-134. https://doi.org/10.1016/j.molstruc.2014.12.031.

[21] S. Edition, MODERN FERRITE TECHNOLOGY, n.d.

[22] A.B. Rajput, S. Hazra, N.N. Ghosh, Synthesis and characterisation of pure single-phase CoFe 2 O 4 nanopowder via a simple aqueous solution-based EDTA-precursor route, 8 (2013) 629-639. https://doi.org/10.1080/17458080.2011.582170. 
[23] K. Samikannu, Sol-gel auto-combustion synthesis of cobalt ferrite and it's cytotoxicity properties SOL-GEL AUTO-COMBUSTION SYNTHESIS OF COBALT FERRITE AND IT,$S$ CYTOTOXICITY PROPERTIES, (2013).

[24] K. Samikannu, Cytotoxic Effect Of Nanocrystalline MgFe2O4 Particles For Cancer Cure Cytotoxic Effect of Nanocrystalline MgFe 2 O 4 Particles for, (2013). https://doi.org/10.1155/2013/865024.

[25] K. Shameli, M. Bin Ahmad, S.D. Jazayeri, S. Sedaghat, Synthesis and Characterization of Polyethylene Glycol Mediated Silver Nanoparticles by the Green Method, (2012) 6639-6650. https://doi.org/10.3390/ijms13066639.

[26] S.O. Aisida, P.A. Akpa, I. Ahmad, M. Maaza, F.I. Ezema, Influence of PVA, PVP and PEG doping on the optical, structural, morphological and magnetic properties of zinc ferrite nanoparticles produced by thermal method, Phys. B Condens. Matter. 571 (2019) 130-136. https://doi.org/10.1016/j.physb.2019.07.001.

[27] M.A. Amer, T.M. Meaz, A.G. Mostafa, H.F. El-ghazally, Journal of Magnetism and Magnetic Materials Structural and physical properties of the nano-crystalline Al-substituted $\mathrm{Cr}-\mathrm{Cu}$ ferrite, J. Magn. Magn. Mater. 343 (2013) 286-292. https://doi.org/10.1016/j.jmmm.2013.05.008.

[28] S.A. Saafan, T.M. Meaz, E.H. El-Ghazzawy, M.K. El Nimr, M.M. Ayad, M. Bakr, A.C. and D.C. conductivity of NiZn ferrite nanoparticles in wet and dry conditions, J. Magn. Magn. Mater. 322 (2010) 2369-2374. https://doi.org/10.1016/j.jmmm.2010.02.039.

[29] M.A. Amer, T.M. Meaz, A.G. Mostafa, H.F. El-Ghazally, Structural and physical properties of the nano-crystalline Al-substituted $\mathrm{Cr}-\mathrm{Cu}$ ferrite, J. Magn. Magn. Mater. 343 (2013) 286-292. https://doi.org/10.1016/j.jmmm.2013.05.008.

[30] M.M. Ismail, S.N. Rafeeq, J.M.A. Sulaiman, A. Mandal, Electromagnetic interference shielding and microwave absorption properties of cobalt ferrite $\mathrm{CoFe} 2 \mathrm{O} 4 /$ polyaniline composite, Appl. Phys. A Mater. Sci. Process. 124 (2018) 1-12. https://doi.org/10.1007/s00339-018-1808-x.

[31] H. Khedri, A. Gholizadeh, Experimental comparison of structural, magnetic and elastic properties of $\mathrm{M} 0.3 \mathrm{Cu} 0.2 \mathrm{Zn} 0.5 \mathrm{Fe} 2 \mathrm{O} 4(\mathrm{M}=\mathrm{Cu}, \mathrm{Mn}, \mathrm{Fe}, \mathrm{Co}, \mathrm{Ni}, \mathrm{Mg})$ nanoparticles, Appl. Phys. A Mater. Sci. Process. 125 (2019) 1-13. https://doi.org/10.1007/s00339-019-3010-1.

[32] E.H. El-Ghazzawy, M.A. Amer, Structural, elastic and magnetic studies of the as-synthesized Co1-xSrxFe2O4nanoparticles, J. Alloys Compd. $690 \quad$ (2017) 293-303. https://doi.org/10.1016/j.jallcom.2016.08.135.

[33] Y. Wang, L. Li, J. Jiang, H. Liu, H. Qiu, F. Xu, Conductivity and magnetic properties of $\mathrm{Zn} 0.6 \mathrm{Cu} 0.4 \mathrm{Cr} 0.5 \mathrm{La} 0.04 \mathrm{Fe} 1.46 \mathrm{O} 4 / \mathrm{PPy}$ composites prepared by in situ inverse microemulsion polymerization, React. Funct. Polym. 68 (2008) 1587-1593. https://doi.org/10.1016/j.reactfunctpolym.2008.08.013.

[34] M.A. Darwish, S.A. Saafan, D. El- Kony, N.A. Salahuddin, Preparation and investigation of dc conductivity and relative permeability of epoxy/Li-Ni-Zn ferrite composites, J. Magn. Magn. Mater. 385 (2015) 99-106. https://doi.org/10.1016/j.jmmm.2015.02.068.

[35] F. Aen, M. Ahmad, M.U. Rana, The role of Ga substitution on magnetic and electromagnetic properties of nano-sized W-type hexagonal ferrites, Curr. Appl. Phys. 13 (2013) 41-46. https://doi.org/10.1016/j.cap.2012.06.014. 